\title{
REDUCTION IN AGRICULTURAL TAX AND THE INCOME GROWTH OF RURAL RESIDENTS: AN EMPIRICAL STUDY
}

\author{
Ruiping Xie ${ }^{1, *}$, Fanling Sun ${ }^{1}$ \\ ${ }^{1}$ Department of Public Economics, Xiamen University, Xiamen 361005, P. R. China \\ * Corresponding author, Address: P. O. Box 79, Department of Public Economics, Xiamen \\ University, Xiamen 361005, P. R. China, Tel: +86-13385926856, Fax: +86-592-2182136, \\ Email:rpxie@163.com
}

\begin{abstract}
Based on the Chinese statistics from 1976 to 2004, this paper conducts an empirical study on the relationship between reduction in agricultural tax and income growth of rural residents by using econometric methodologies of cointegration theory and error correction mechanism. The result reveals that the policy of reducing agricultural tax has a positive effect on the whole level of peasant's income, but this measure won't resolve the problem of a long-term and continuous growth in peasant's income. In the short run, reduction in agricultural tax obviously increases the direct income of farmers; while in the long run; household operational income and wage income are key elements of peasant's income growth.
\end{abstract}

Keywords: agricultural tax, reduction, income growth, empirical research

\section{INTRODUCTION}

During the 1990s, with high economic growth rate in China, the growth rate of the peasant's income was relatively low and the problem of peasant's economic burden was increasingly worsening. In order to raise peasant's income, the central government conducted the rural tax \& fee reform from the beginning of 2000, aiming at straightening out the distributive relations among government, collective and farmers and actually slashing peasant's burden. From 2000 to 2003, China started to undertake experiments in Anhui 
Province and then gradually generalized to the whole country. The government has conducted trials on reduction and exemption in agricultural tax since 2004. "Central No. 1 document" puts forward that "agricultural tax rate will be cut down by one percentage point in average", and at the National People's Congress it was announced that the rate of agricultural tax would be reduced yearly by more than one percentage point until it was cancelled five years later. One year after, the reducing term was shortened to three years. On December 29, 2005, the 19th Meeting of the Tenth Standing Committee of the National People's Congress passed the decision concerning abolishing the agricultural taxation regulation by an overwhelming majority vote. This policy is branded as the most important reforming measures after the implementation of family-contract responsibility system in China. In order to understand the effects of this reform on peasant's income growth, an empirical analysis, through the econometric methodologies of co-integration theory and error correction mechanism, is carried out, covering the relevant data from 1976 to 2004.

On the relations of reduction in agricultural tax and the income growth of rural residents, there exist three kinds of standpoints. The first standpoint is that the rural tax-fee reform is the efficient path to raise peasant's income (David E. Sahn et al., 1996; Alex Winter-Nelson, 1997; Christine A. Wilson et al., 2002; Yifu Lin, 2003; Li-an Zhou \& Ye Chen, 2005). The second standpoint puts forward that the rural tax - fee reform isn't as important as expected, even though the short-term result is significant, the long-term result is uncertain (Robert G. Chambers, 1995; Hui Qin, 2003; Qiyun Fang et al., 2005). The third standpoint reveals that the rural tax - fee reform does little help to the farmers, so maybe agricultural tax shouldn't be reduced or exempted (Mahmood Hasan Khan, 2001; David M. Newbery, 1992; Daiyan Peng, 2004; Junchu Zhu, 2005).

According to these standpoints above, we will carry out an empirical study to reveal whether this policy really reduce the peasant's burden and increases their income. At the same time, we will also try to analyze the scope of change in peasant's income and the time span of this effect.

\section{BASIC MODELING}

In the yearbook entitled The Agricultural Statistical Annual of China, the peasant's net income consists of wage income, household operational income, property income, transfer income and other incomes. Because, relatively speaking, property income, transfer income and other incomes are just a fraction of the total income, so to reduce the loss of the freedom degree, we combine these three parts into one variable. Therefore we have $Y_{0}=X_{1}+X_{2}+X_{3}$, where $Y_{0}$ represents the peasant's net income, $X_{I}$ represents 
wage income, $X_{2}$ represents the peasant's household operational income, $X_{3}$ represents the total of property income, transfer income and other incomes. The distribution of the peasant's net income includes the profit deduction and reservation for the collective, national tax and peasant's household income. To reveal the relationship between agricultural tax and the peasant's income growth, we introduce the variable $\mathrm{T}$ which stands for agricultural tax. Hence we have $Y_{0}-T=X_{1}+X_{2}+X_{3}-T$. Set $Y=Y_{0}-T$, thus $Y$ represents the aftertax net income, therefore $Y=X_{1}+X_{2}+X_{3}-T$. So $Y$ then can be rendered as the function of $X_{1}, X_{2}, X_{3}$ and $T: Y=\mathrm{F}\left(X 1, X_{2}, X_{3}, T\right)$. Differentiate it with respect to $X_{1}$, we get:

$$
d Y=\frac{\partial Y}{\partial X_{1}} d X_{1}+\frac{\partial Y}{\partial X_{2}} d X_{2}+\frac{\partial Y}{\partial X_{3}} d X_{3}+\frac{\partial Y}{\partial T} d T
$$

Divide (1) by $Y$, then we obtain:

$$
\frac{d Y}{Y}=\frac{X_{1}}{Y} \frac{\partial Y}{\partial X_{1}} \frac{d X_{1}}{X_{1}}+\frac{X_{2}}{Y} \frac{\partial Y}{\partial X_{2}} \frac{d X_{2}}{X_{2}}+\frac{X_{3}}{Y} \frac{\partial Y}{\partial X_{3}} \frac{d X_{3}}{X_{3}}+\frac{T}{Y} \frac{\partial Y}{\partial T} \frac{d T}{T}
$$

where: $\frac{X i}{Y} \frac{\partial Y}{\partial X i}(\mathrm{I}=1,2,3)$ represents the after-tax net income Y's elasticity of $\mathrm{X}_{1}$, abbreviated as $\alpha_{\mathrm{i}}, \frac{T}{Y} \frac{\partial}{\partial T}$ denotes the after-tax net income Y's elasticity of the agricultural tax T, abbreviated as $\beta, \frac{d Y}{Y}$ can be taken as the growth rate of $\mathrm{Y}$, abbreviated as $R Y, \frac{d X i}{X i}$ can be seen as the growth rate

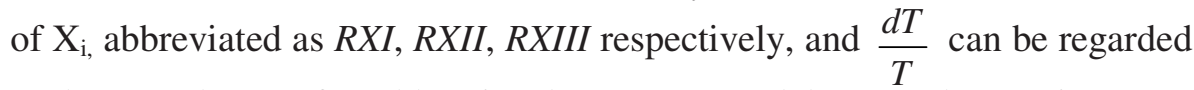
as the growth rate of $\mathrm{T}$, abbreviated as $R T$. So model (2) can be rewritten as:

$$
R Y=\alpha_{1} R X I+\alpha_{2} R X I I+\alpha_{3} R X I I I+\beta R T
$$

\section{STATISTICS CHECKING AND EMPIRICAL RESULT}

Statistics checking: We get the sample annual data from 1976 to 2004 of peasant's net income per capita, peasant's household operational net income per capita, peasant's average wage income per capita, peasant's average property income per capita and average transfer income per capita from the yearbook entitled The 2005 Rural Statistical Annual of China and the agricultural tax data from the yearbook entitled The 2005 Financial Statistical Annual of China, the population data of the rural areas comes 
from the yearbook entitled The 2005 China Population Statistics Annual, the amount of average burden per farmer equals to the ratio of total agricultural tax and the agricultural population. All variables above are real ones. We get the real values adjusted to GDP deflation index with 1978 as the base year.

\subsection{The stationary Test of stochastic series}

With EVIEWS5.0, through which all the following results are obtained, we get the Unit Root Testing results of each variable as shown in Table 1:

Table 1. Unit Root Testing

\begin{tabular}{lccc}
\hline Variables & Testing Form & ADF Value & P Value \\
\hline$R Y$ & $0, \mathrm{Y}, \mathrm{N}$ & -2.906 & 0.0588 \\
$R Y$ & $1, \mathrm{Y}, \mathrm{N}$ & -6.166 & 0.0000 \\
$R X I$ & $0, \mathrm{Y}, \mathrm{N}$ & -2.657 & 0.0100 \\
$R X I I$ & $0, \mathrm{Y}, \mathrm{N}$ & -2.865 & 0.0060 \\
$R X I I I$ & $0, \mathrm{Y}, \mathrm{N}$ & -4.117 & 0.0037 \\
$R T$ & $0, \mathrm{Y}, \mathrm{N}$ & -4.192 & 0.0002 \\
\hline
\end{tabular}

Note: the sign patterns in the testing form from left to right respectively mean difference orders, constant item and time trend item. 0 means no difference and 1 means difference order is one and so on. Y means that there has a constant item or time trend item, while $\mathrm{N}$ means the opposite.

The results of the unit root test show that, under the significance level of 0.01 , variables $R X I, R X I I, R X I I I$ and $R T$ have no unit roots and they are all stationary time series; while variable $R Y$ is a non-stationary series even with significance level of 0.05 , actually it is integrated of order 1 . Therefore we could proceed to analyze whether there's a co-integration relationship between dependent variable and independent variables.

\subsection{Co-integration test}

The model (3) is regressed, and the results are as follows:

$$
\begin{array}{lccc}
R Y_{t}=0.4627 R X I_{\mathrm{t}}+ & 0.3581 R X I I_{\mathrm{t}}+ & 0.0653 R X I I I_{\mathrm{t}} & -0.0431 R T_{\mathrm{t}}+\mathrm{u}_{\mathrm{t}} \\
\mathrm{t} \text { statistic }(12.49) & (16.24) & (2.32) & (-1.53) \\
\mathrm{P} \text { value } 0.0000^{*} & 0.0000 * & 0.0299 & 0.1394 \\
\mathrm{R}^{\wedge} 2=0.8703 \mathrm{DW}=2.3029 & &
\end{array}
$$

Taking a unit root test on model (4)'s residual error gives the results as shown in Table 2.

Table 2. Co-integration test

\begin{tabular}{|c|l|c|c|c|}
\hline ADF Value & Testing & \multicolumn{3}{|c|}{ Critical Value } \\
\cline { 3 - 5 } & Form & 0.01 Level & 0.05 Level & 0.10 Level \\
\hline-6.6231 & $0, \mathrm{~N}, \mathrm{~N}$ & -2.6570 & -1.9544 & -1.6093 \\
\hline
\end{tabular}


Under the significance level of 0.01 , the ADF value of the residual, which is -6.6231 , is less than the critical value $(-2.6570)$. So the residual of the model (4) is reposeful and the equation (4) is co-integration regression, which means there is a co-integrated relationship among variables $R X I, R X I I$, $R X I I I, R T$ and $R Y$. And model (4) is the function of long-term relation among these variables. Each regression coefficient stands for the long-term elasticity. Although the parameter values of $R X I, R X I I$ are statistically significant under the significance level of 0.01 and RXIII under the significance level of 0.05 , while the parameter value of $R T$ is not statistically significant even with the significance level of 0.05 , so relevant examination and revision to model (4) are carried out.

The Test for Heteroscedasticity: Because sample data has only 28 observations (a small sample), so we adopt Goldfeld-Guandt Test to test the Heteroscedasticity. After sequencing the data according to the $R T$, depriving the middle 4 observations, we do OLS regression on the top 12 observations and the bottom 12 observations respectively and get their residual sum of squares (rss1 and rss2), therefore we know $F=\frac{r s s 1 / d f 1}{r s s 2 / d f 2}=50.40$, with significance level of $5 \%$ which is more than the critical value under the freedom degree of 7 for the denominator and 7 for the numerator, that is to say, the residual has the quality of conditional (Heteroskedasticity) relation. Using White Test, we will get the same conclusion.

To eliminate the Heteroskedasticity, we use White heteroscedasticity correction and get the following result:

$$
\begin{aligned}
& R Y_{t}=0.4627 R X I_{\mathrm{t}}+0.3581 R X I I_{\mathrm{t}}+0.0653 R X I I I_{\mathrm{t}}-0.0431 R T_{\mathrm{t}}+\mathrm{u}_{\mathrm{t}} \\
& \text { t statistic (16.37) (20.17) (2.89) } \\
& \begin{array}{lllll}
P \text { value } & 0.0000 & 0.0000 & 0.0083 & 0.0180
\end{array} \\
& \mathrm{R}^{\wedge} 2=0.8703 \quad \mathrm{DW}=2.3029
\end{aligned}
$$

After the White heteroscedasticity correction, there is no difference for the value of each coefficient, but they are more statistically significant. Variables $R X I, R X I I, R X I I I$ are all statistically significant with significance level of 0.01 , so is the variable RT with significance level of 0.05 . Therefore model (5) makes a more accurate simulation about the long-term relationship between the independent variables and dependent variable.

Model (5) expresses that during the sample period, the growth rate of the peasant's wage income $(R X I)$, the growth rate of peasant's household operational income $(R X I I)$ and the growth rate of peasant's property income and transfer income (RXIII) all have positive effects on peasant's after-tax income RY. Among them, the growth rate of the wage income and household operational income are the predominant factors. If $R X I, R X I I$ and RXIII change $1 \%$ respectively, accordingly, the peasant's after-tax income 
will change $0.4627 \%, 0.3581 \%$ and $0.0653 \%$ in the same direction. However the coefficient of variable $R T$ (the agricultural tax) is negative, which means the rise in the agricultural tax will bring negative influence to peasant's income. This also indicates that the policy of reducing agricultural tax is advantageous to the growth of peasant's income per capita. Compared to several other factors in the model, the agricultural tax is the one over which the government can exert the most direct control. So reducing agricultural tax has become one of the most efficient means for the government to work on the peasant's income in recent years.

The coefficient of $R T$ is 0.0431 , which reveals if the government reduces the agricultural tax by $1 \%$ each time, the peasant's real net income will increase by $0.0431 \%$. Therefore, the effect on the growth of peasant's income, brought about by the reduction in the agricultural tax, depends on the degree of the reduction, the larger the reduction is, the more significant the effect is; the shorter the time span is, the more remarkable the effect will be. If the government exempted the agricultural tax, peasant's net income per capita would increase by $4.31 \%$, which makes peasant's overall income rise to a new level. If the agricultural tax is cut down year by year, the effect is also apportioned to the same period. For example, if we carry on a calculation to the sample data, we can get that, during the sample period, peasant's real net income per capita will increase by $7.5 \%$ every year. Therefore, if the agricultural tax is reduced within one year, the direct contribution rate to peasant's income growth rate is $4.31 / 7.5 * 100 \%=57.5 \%$; If this period is increased to 5 years, then the contribution rate will decrease to $12.5 \%$. Actually, many provinces have started reducing the agricultural tax since 2000 and adhered to such measure until the nation declares to abolish the agricultural tax in the whole nation in 2006.

\subsection{The error correction mechanism}

We have already proven that there exists a co-integrated relationship between RXI, RXII, RXIII, RT and $R Y$, which means they have an equilibrium relationship in the long term. However, in the short term, variations in the dependant variable will generate dependant variable's deviation from equilibrium. And the error in model (5) can be regarded as "equilibrium error". With this error and ECM, we can relate the short-term behavior with its long-term equilibrium value. Making use of the relevant time series of model (5), an appropriate Error Correction Mechanism and White heteroscedasticity correction, we get the following result:

$$
\begin{aligned}
& \Delta R Y_{t}=0.3541 \Delta R X I_{\mathrm{t}}+0.4614 \Delta R X I I_{\mathrm{t}}+0.0548 \Delta R X I I I_{\mathrm{t}^{-}}-0.0399 \Delta R T_{\mathrm{t}}-1.1881 \mathrm{u}_{\mathrm{t}-1}+\varepsilon_{\mathrm{t}} \\
& \text { t statistic } 9.3735 \\
& 8.9481 \\
& 2.2074 \\
& 1.9040 \\
& -5.7472 \\
& P \text { value } \quad 0.0000 \quad 0.0000 \\
& 0.0447 \\
& 0.0106 \\
& 0.0000 \\
& \mathrm{R}^{2}=0.854 \mathrm{DW}=1.9274
\end{aligned}
$$


Where: $\Delta$ means a One order Difference, $\varepsilon_{\mathrm{t}}$ is the stochastic error, derived from model (5), which equals to $\mathrm{u}_{\mathrm{t}-1}=R Y_{t}-0.4627 R X I_{\mathrm{t}}-0.3581 R X I I_{\mathrm{t}}-$ $0.0653 R X I I I_{\mathrm{t}}+0.0431 R T_{\mathrm{t}}$. Equation (6) expresses the $\Delta R Y$ is decided by $\Delta R X I, \Delta R X I I, \Delta R X I I I, \Delta R T$ and equilibrium error. If the latter is not zero, the model then deviates from the equilibrium state. The coefficient of $\mathrm{u}$ is negative, so if there is a positive deviation in the former period, then the deviation will be corrected by the negative error item, which brings the model back to the equilibrium states, so is the negative deviation. The absolute value of the coefficient of $\mathrm{u}_{\mathrm{t}-1}$ is to 1.188 , so the deviation will diminish in a very short time. Just as the results given by the analysis above, we will come to the conclusion that the short-term changes in the peasant 's household operational income per capita, the average wage income per capita, the average property income per capita and the average transfer income per capita data all have positive influence on the peasant's after-tax income per capita, while the rise of the agricultural tax per peasant has a negative impact. At the same time, the absolute value of the short-term effect coefficient (-0.0399) is smaller than the long-term effect coefficient $(-0.0431)$, as given by equation (5). One explanation to this maybe that there exists a time lag before the policy takes effect and the peasants change their production plans. While in the long run, peasants have adequate time to make adjustments to avoid this time lag.

\section{CONCLUSIONS}

After the empirical analysis on the relationship between reduction in agricultural tax and peasant's income growth, we get conclusions as follows:

1. There exists a long-term equilibrium relationship between the peasant's net income per capita and the reduction of agricultural tax. Reduction or exemption in agricultural tax has long-term effect on the growth of peasant's income. If agricultural tax were abolished, peasant's overall net income per capita would increase by $4.31 \%$ compared to the agricultural tax case.

2. The short-term impact of reducing agricultural tax is relative to the degree of reduction and time span. If the agricultural tax is reduced to zero in a very short time, e.g. one year, then the effects will be very remarkable.

3. After the abolishment of agricultural tax, there is no continuing effect from the reduction. Therefore, in the long-term perspective; such policy can't guarantee the continuous growth of peasant's income. While peasant's wage income and household operational income plays a key place in their income growth, especially their wage income. 
To sum up, reducing or abolishing agricultural tax has a positive effect on increasing peasant's whole income in the short term; however, this effect is not sustainable in the long-term. Therefore, establishing an effective, long-term mechanism to increase peasant's wage income and household operational income continuously and steadily is the foundation to the growth of peasant's income.

\section{ACKNOWLEDGEMENTS}

This paper has been funded by the project of National Social Science Foundation of China (NO. 07CJL027).

\section{REFERENCES}

Alex Winter-Nelson 1997. Rural taxation in Ethiopia 1981-1989: a policy analysis matrix assessment for net producers and net consumers, Food Policy, 5: 419-431

Christine A. et al. The effects of a federal flat tax on agriculture, Review of Agricultural Economics, 2002, 24: 160-180

Daiyan Peng. The rural tax-fee reform, the polarization of village leaders and the transformation of social contradiction - according to the analysis about findings in rural areas of Hubei, Journal of Nanjing Administrative Institute and The Nanjing Party School, 2004, 4: 58-62 (in Chinese)

David E. Sahn et al. Exchange rate, fiscal and agricultural policies in Africa: Does adjustment hurt the poor. World Development, 1996, 4: 719-747

David M. Newbery. Agricultural pricing and public investment, Journal of Public Economics, 1992, 2: 253-271

Hui Qin. "Huang Zhongxi laws" and system foundation of tax-fee reform: historical experience and the selection of reality, Tax Administration Research, 2003, 7: 2-8 (in Chinese)

Junchu Zhu. Unscramble reducing agricultural tax and peasants' income growth, Beijing Youth Daily, 2003, 1: 22 (in Chinese)

Li-an, Zhou, Ye Chen. The policy effect of tax - and - fees reforms in rural China: a differencein-differences, Economy Research, 2005, 8: 44-53 (in Chinese)

Mahmood Hasan Khan. Agricultural taxation in developing countries: a survey of issues and policy. Agricultural Economics, 2001, 3: 315-328

Qiyun Fang et al. An empirical study of the influences of rural tax - fee reform on peasant's income, Chinese Rural Economy, 2005, 5: 36-38 (in Chinese)

Robert G. Chambers. The incidence of agricultural policies, Journal of Public Economics, 1995, 2: 317-335

Yifu Lin. Some opinions relevant to current rural policy, The Problem of Agricultural Economy, 2003, 6: 4-7 (in Chinese) 